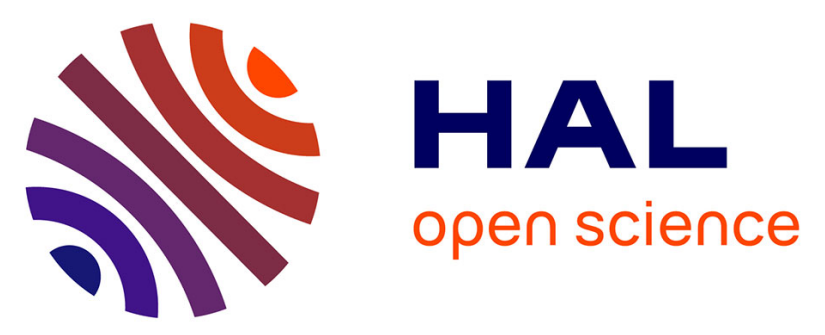

\title{
Effect of the counter cation on the third order nonlinearity in anionic Au dithiolene complexes
}

Konstantinos Iliopoulos, Abdelkrim El-Ghayoury, Beata Derkowska-Zielinska, Anupama Ranganathan, Patrick Batail, Denis Gindre, Bouchta Sahraoui

\section{- To cite this version:}

Konstantinos Iliopoulos, Abdelkrim El-Ghayoury, Beata Derkowska-Zielinska, Anupama Ranganathan, Patrick Batail, et al.. Effect of the counter cation on the third order nonlinearity in anionic Au dithiolene complexes. Applied Physics Letters, 2012, 101 (26), pp.261105. 10.1063/1.4772476 . hal-01389336

\section{HAL Id: hal-01389336 https://hal.science/hal-01389336}

Submitted on 8 Oct 2021

HAL is a multi-disciplinary open access archive for the deposit and dissemination of scientific research documents, whether they are published or not. The documents may come from teaching and research institutions in France or abroad, or from public or private research centers.
L'archive ouverte pluridisciplinaire HAL, est destinée au dépôt et à la diffusion de documents scientifiques de niveau recherche, publiés ou non, émanant des établissements d'enseignement et de recherche français ou étrangers, des laboratoires publics ou privés. 


\title{
Effect of the counter cation on the third order nonlinearity in anionic Au dithiolene complexes
}

\author{
K. Iliopoulos, ${ }^{1,2}$ A. El-Ghayoury, ${ }^{1, a)}$ B. Derkowska, ${ }^{3}$ A. Ranganathan, ${ }^{1}$ P. Batail, ${ }^{1}$ D. Gindre, ${ }^{1}$ \\ and B. Sahraoui ${ }^{1, b)}$ \\ ${ }^{1}$ LUNAM Université, Université d'Angers, CNRS UMR 6200, Laboratoire MOLTECH-Anjou, 2 Bd Lavoisier, \\ 49045 Angers Cedex, France \\ ${ }^{2}$ Institute of Chemical Engineering Sciences, Foundation for Research and Technology Hellas (FORTH/ICE-HT), \\ 26504 Patras, Greece \\ ${ }^{3}$ Institute of Physics, N. Copernicus University, Grudziadzka 5/7, 87-100 Toruń, Poland
}

(Received 27 September 2012; accepted 3 December 2012; published online 27 December 2012)

\begin{abstract}
In this work, we present the third order nonlinear optical investigation of two gold complexes, which differ by the nature of the counter cations. The impact of the different design in the architecture through a set of hydrogen bonds in the case of Au-Mel of the systems on the nonlinearity has been studied by means of the Z-scan setup under $532 \mathrm{~nm}, 30 \mathrm{ps}$ laser excitation, allowing for the determination of the nonlinear absorption and refraction of the samples. Significant modification of the nonlinear optical response between the two metal complexes has been found suggesting a clear effect of the counter cation. (C) 2012 American Institute of Physics. [http://dx.doi.org/10.1063/1.4772476]
\end{abstract}

Nonlinear optical (NLO) materials are widely investigated as promising candidates for a variety of applications such as optical communications, optical storage, optical computing, harmonic light generation, optical power limiting, optical rectifying devices, displays, printers, dynamic holography, frequency mixing, and optical switching ${ }^{1-3}$ for which large second order and/or third order nonlinear optical responses are a prerequisite. In the search for efficient NLO molecular systems, ${ }^{4-7}$ dithiolene metal complexes have been widely investigated. Due to their interesting electronic properties, they have been used for the preparation of singlecomponent molecular metals ${ }^{8,9}$ and molecular conductors and superconductors. ${ }^{10,11}$ These properties are inherent to an extended delocalized $\pi$ system which, in addition, makes them among the most promising candidates as efficient NLO molecular systems. ${ }^{7,12-14}$ Another advantage of these systems is that the NLO response can be tailored to match specific applications by changing their structure through the modification of the ligands, ${ }^{12}$ the change of counter cations, ${ }^{14}$ or even the oxidation state of the core metal. ${ }^{14,15}$

In this work, we report on the nonlinear optical response of $\left[\mathrm{Au}(\mathrm{midt})_{2}\right]^{-} \mathrm{PPh}_{4}{ }^{+}$, a gold(III) maleimide dithiolate tetraphenylphosphonium salt designated as Au-P, and a gold(III) maleimide dithiolate melamine melaminium hybrid solvate, $\left(\mathrm{C}_{3} \mathrm{~N}_{6} \mathrm{H}_{6}\right)\left(\mathrm{C}_{3} \mathrm{~N}_{6} \mathrm{H}_{7}^{+}\right)\left[\mathrm{Au}(\text { midt })_{2}\right]^{-} \cdot 2 \mathrm{DMF} \cdot 2 \mathrm{H}_{2} \mathrm{O}$, designated as Au-Mel (Scheme 1). These two salts, which differ mainly by the nature of the counter cations were prepared as previously described. ${ }^{16}$ The counter cations were chosen in order to have in the first case a simple electrostatic interaction between the two molecular ions. In the second case, the use of the melaminium cation $\left(\mathrm{Mel}^{+}\right.$, Scheme 2) provides for a charge-assisted set of hydrogen bond interactions involving the hydrogen bond donor/acceptor metal dithiolene complex anion which effectively directs an extended two-dimensional

\footnotetext{
${ }^{a}$ Electronic mail: abdelkrim.elghayoury@univ-angers.fr.

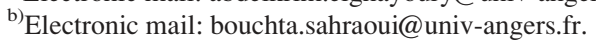

crystalline structure. The NLO properties of these materials have been investigated in order to elucidate the difference of the response between the two metal complexes and to investigate the effect of the charge-assisted hydrogen bond network on the nonlinearity, as it is likely to be effective already in the liquid phase. The NLO measurements were done employing the Z-scan technique, ${ }^{17}$ utilizing a diode pumped passively mode-locked $\mathrm{Nd}: \mathrm{YVO}_{4}$ laser with a repetition rate of $10 \mathrm{~Hz}$ delivering $30 \mathrm{ps}$ laser pulses at $532 \mathrm{~nm}$. By means of this setup, the real (related with nonlinear refraction) and imaginary (related with nonlinear absorption) parts of the third order nonlinear susceptibility $\left(\chi^{(3)}\right)$, as well as their signs, have been separately determined.

For the needs of the NLO measurements, different concentrations of the samples have been prepared and put into $1 \mathrm{~mm}$ quartz cuvettes in order to be studied. Then "open aperture" and "closed aperture" Z-scan curves have been obtained by measuring the transmittance of the laser beam after the sample. In the case of the "open aperture" Z-scan, all the laser beam has been collected by a focusing lens and then detected by a photomultiplier. In the second case, only the part of the beam passing through a narrow aperture has been detected. From the "open aperture" curves, the nonlinear absorption coefficient $\beta$ has been deduced by means of the following equation:

$$
T=\sum_{m=0}^{\infty} \frac{\left[-\beta I_{0} L_{e f f} /\left(1+z^{2} / z_{0}^{2}\right)\right]^{m}}{(m+1)^{3 / 2}},
$$

where $T$ is the normalized transmittance, $L_{e f f}=(1-\exp$ $\left.\left(-\alpha_{0} L\right)\right) / a_{0}$ is the effective thickness of the sample $\left(\alpha_{0}\right.$ is the linear absorption coefficient at the laser excitation wavelength), and $\mathrm{I}_{0}$ is the on-axis irradiance at the focus.

By dividing the "closed aperture" Z-scan by the "open aperture," the "divided" Z-scan is obtained, which allows for the determination of the nonlinear refraction. More specifically, the nonlinear refractive parameter $\gamma^{\prime}$ can be determined by fitting the data according to the equation 

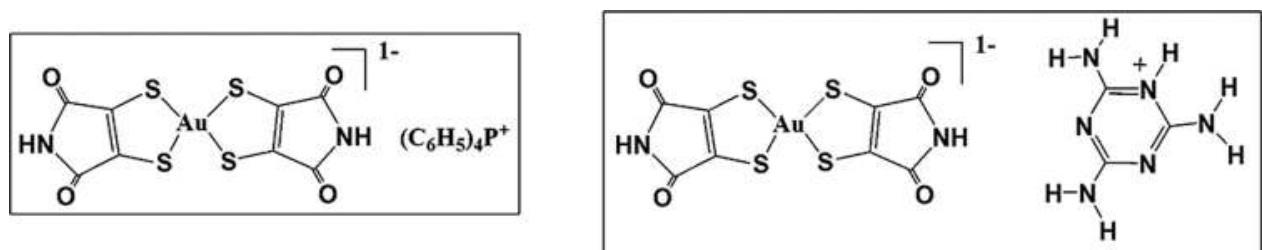

SCHEME 1. Schematic drawing of the studied complexes.
Au-P

$$
T=1+\frac{4 \Delta \Phi_{0} x}{\left(x^{2}+9\right)\left(x^{2}+1\right)},
$$

where $\Delta \Phi_{0}=k I_{0} \gamma^{\prime} L_{\text {eff }}$ is the nonlinear phase shift.

Knowing the $\beta$ and $\gamma^{\prime}$, the imaginary and real parts of the third order nonlinear susceptibility can be determined using the following equations:

$$
\begin{gathered}
\operatorname{Im} \chi^{(3)}(e s u)=\frac{10^{-7} c^{2} n_{0}^{2}}{\left(96 \pi^{2} \omega\right)} \beta\left(\mathrm{cmW}^{-1}\right) \\
\operatorname{Re} \chi^{(3)}(e s u)=\frac{10^{-6} c n_{0}^{2}}{480 \pi^{2}} \gamma^{\prime}\left(\mathrm{cm}^{2} \mathrm{~W}^{-1}\right) .
\end{gathered}
$$

In these equations, $\mathrm{c}$ is the speed of light in $\mathrm{cm} \mathrm{s}^{-1}$ and $\omega$ is the fundamental frequency in cycles $\mathrm{s}^{-1}$. Finally, the second order hyperpolarizability $\gamma$, which is not concentration dependent and depends only on the molecular system itself, has been determined using the following equation:

$$
\gamma=\frac{\chi^{(3)}}{N L^{4}}
$$

where $N$ is the number density and $L$ is the local field correction factor.

In Figure 1, characteristic electronic absorption spectra of $1.2 \times 10^{-4} \mathrm{M}$ dimethylformamide (DMF) solutions of complexes Au-P and Au-Mel are presented. They exhibit a strong electronic absorption band in the UV region, which is attributed to $n-\pi$ transition and an electronic band in the visible region which is the characteristic of $d-p$ interaction, while there is no strong interaction in the NIR region since these complexes are $\mathrm{d}^{8}$ type. ${ }^{18}$

Several different concentrations have been studied for each system with the Z-scan technique, while for each one, energy-dependent measurements have been done in order to verify the third-order nonlinear character of the response and that no saturation of the response was taking place during the measurements. The solvent has been found to have signifi-

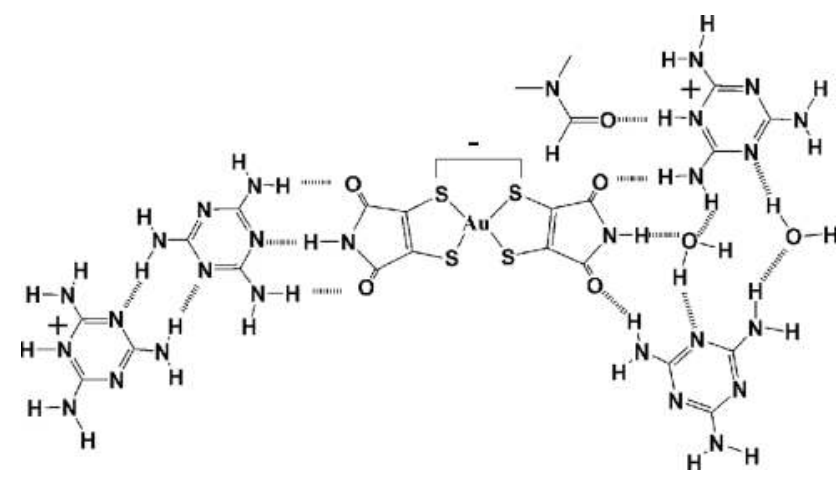

SCHEME 2. Hydrogen bond pattern within Au-Mel complex.
Au-Mel

cant nonlinear refraction, so it has been in all cases separately investigated and the contribution has been taken into account in order to determine the nonlinear refraction emanating from the samples. On the contrary, the "open aperture" Z-scans of the solvent have been flat indicating that there was no contribution of the solvent to the nonlinear absorption, at least under the same experimental conditions. Moreover, for the derivation of the nonlinear optical parameters, the linear absorption of the samples at the laser excitation wavelength $(532 \mathrm{~nm})$ has been taken into account.

The "open aperture" Z-scans of the samples having concentrations $1.5-2.0 \mathrm{mM}$ have been found to exhibit transmittance minima characteristic of the reverse saturable absorption (RSA) character, while for lower concentrations the nonlinear absorption has been found to be negligible. Moreover, the "divided" Z-scans exhibited valley-peak configuration indicative of self-focusing action of the materials, while the contribution of the solvent has in all cases measured and removed in order to determine the $\operatorname{Re} \chi^{(3)}$ of the systems. Characteristic "divided" and "open aperture" Z-scans can be seen in Figure 2 corresponding to an AuM solution in DMF $(2.0 \mathrm{mM})$. From a plethora of divided Z-scans obtained for each concentration, the real part of the third order nonlinear susceptibility has been obtained according to Eqs. (2) and (3) and is presented in Figure 3 as a function of the concentration for the two investigated molecular systems. It is obvious from this figure that no saturation of the nonlinear optical response takes place within the utilized range of concentration. It should be noted that the linear absorption has been taken into account in our calculations (through Eqs. (2) and (3)), so the difference between the slopes corresponding to the two molecules can be directly related with the different NLO refraction, emanating from the two systems. From

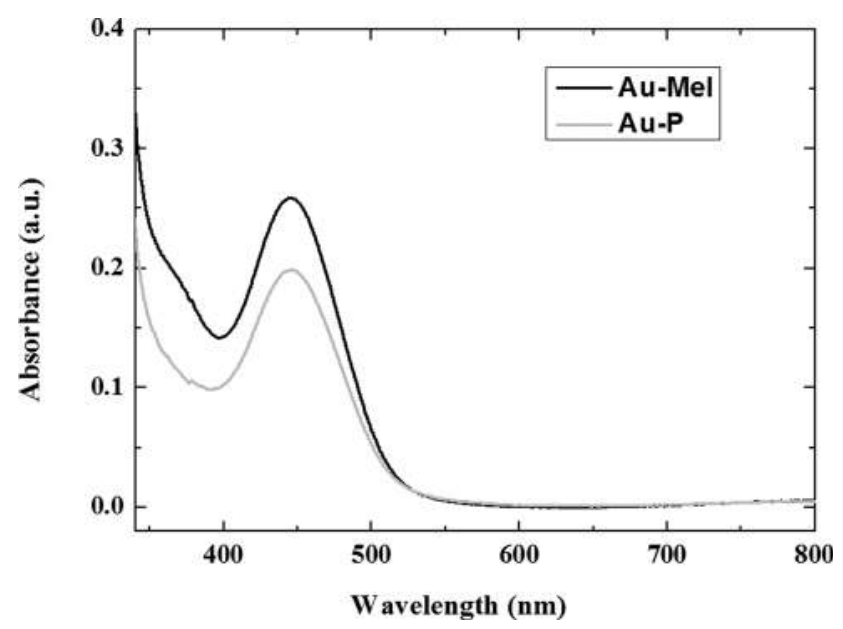

FIG. 1. Absorption spectra of the two complexes Au-P and Au-Mel $\left(1.2 \times 10^{-4} \mathrm{M}\right.$ in DMF). 

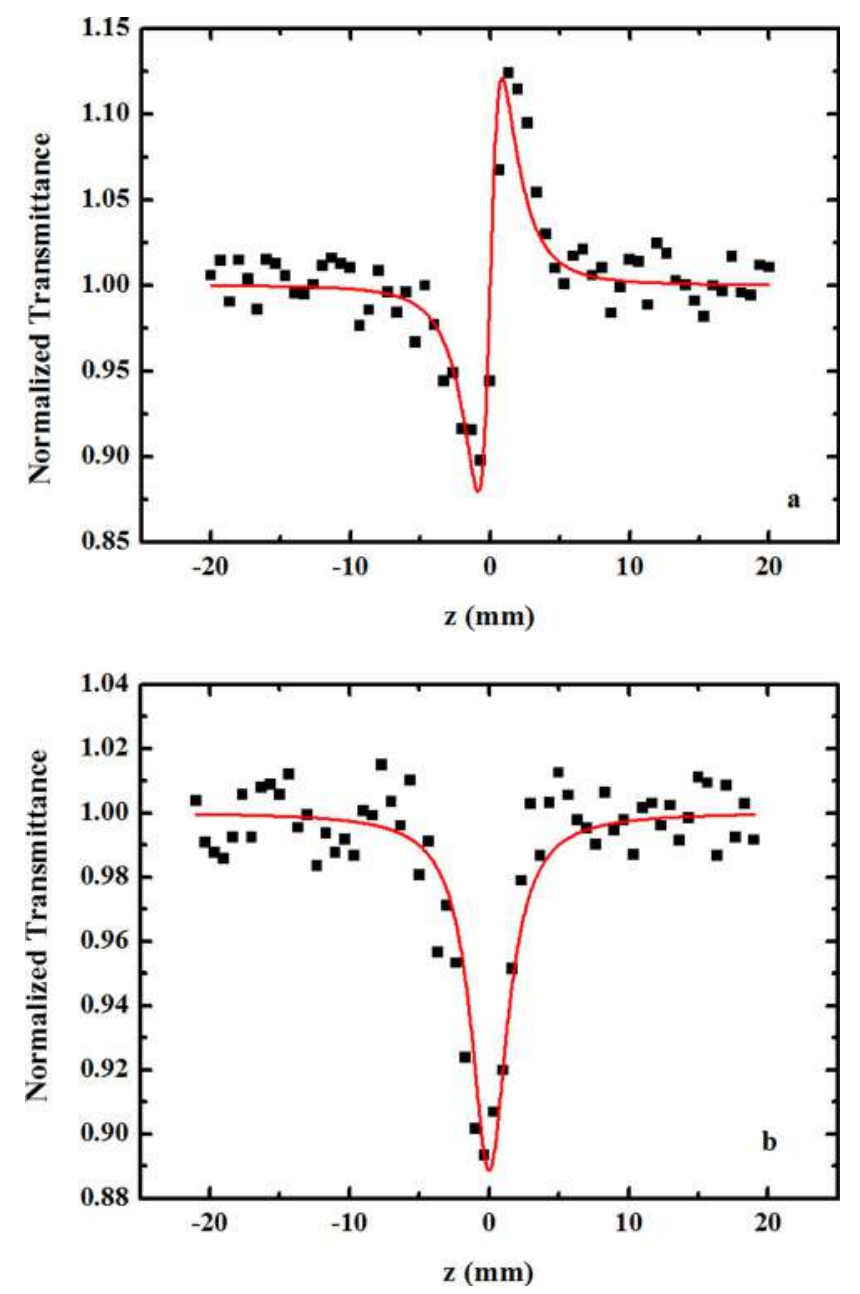

FIG. 2. "Divided" (a) and "open aperture" (b) Z-scans corresponding to an AuM solution in DMF $(2.0 \mathrm{mM})(\mathrm{E}=1.6 \mu \mathrm{J})$.

the slopes of these linear fits and according to Eq. (4), the real part of the second order hyperpolarizability has been determined and has been found to be $0.72 \times 10^{-32}$ esu and $1.9 \times 10^{-32}$ esu for the systems Au-P and Au-Mel, respectively (see also Table I).

Then, using the "open aperture" Z-scan recordings, the nonlinear absorption of the molecules has been determined. In this case, the effect of the solvent has been negligible, so

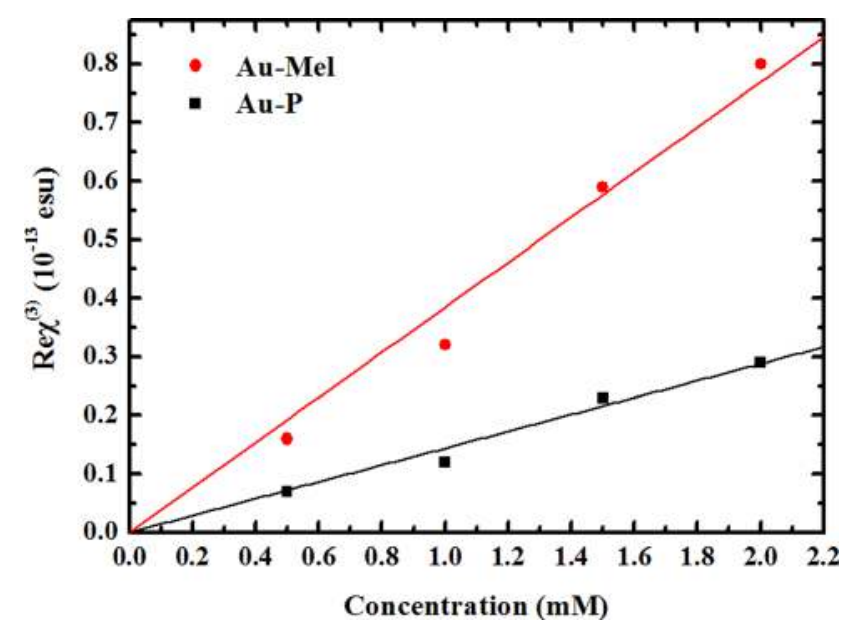

FIG. 3. Concentration dependence of $\operatorname{Re} \chi^{(3)}$ for the two dithiolene gold metal complexes.
TABLE I. Nonlinear optical parameters of the systems Au-Mel and Au-P.

\begin{tabular}{lccc}
\hline \hline & \multicolumn{3}{c}{ Z-scan } \\
\cline { 2 - 4 } Sample & $\operatorname{Re} \gamma\left(10^{-32}\right.$ esu $)$ & $\operatorname{Im} \gamma\left(10^{-32}\right.$ esu $)$ & $\gamma\left(10^{-32}\right.$ esu $)$ \\
\hline Au-Mel & 1.90 & 1.2 & 2.24 \\
Au-P & 0.72 & 0.56 & 0.91 \\
\hline \hline
\end{tabular}

all the response has been attributed to the investigated molecular systems. The imaginary part of the second order hyperpolarizability has been determined according to Eqs. (1), (3), and (4) and it can be seen in Table I. The corresponding $\operatorname{Im} \chi^{(3)}$ values in the case of the $2.0 \mathrm{mM}$ solutions have been found to be $0.224 \times 10^{-13}$ esu and $0.471 \times 10^{-13}$ esu for the systems Au-P and Au-Mel, respectively. As it can be seen from Table I, the Au-Mel system exhibits higher nonlinear refraction and nonlinear absorption, which results in a much higher hyperpolarizability $\gamma$ (by about a factor of 2.5), compared with the Au-P complex. Also, the nonlinear absorption is lower than the refraction for both studied systems, which explains the fact that the nonlinear absorption has been found to be negligible for the lower concentration solutions studied during this work (up to $1.5 \mathrm{mM}$ concentration). The large difference of the $\gamma$ values for the two gold dithiolene complexes can be explained by the presence of two different counter cations in the two metal complexes. In fact, in the case of the complex Au-P, there is no intermolecular interaction between the tetraphenylphosphoinium $\left(\mathrm{C}_{6} \mathrm{H}_{5}\right)_{4} \mathrm{P}^{+}$cation and the gold dithiolene complex. On the contrary, in the case of Au-Mel, the precise, charge-assisted, hydrogen-bonded cation-anion interaction identified in the solid state ${ }^{16}$ is likely to be effective to some significant extend in a DMF solution the gold(III) maleimide dithiolate melamine melaminium hybrid solvate, $\left(\mathrm{C}_{3} \mathrm{~N}_{6} \mathrm{H}_{6}\right)\left(\mathrm{C}_{3} \mathrm{~N}_{6} \mathrm{H}_{7}{ }^{+}\right)$ $\left[\mathrm{Au}(\text { midt })_{2}\right]^{-} \cdot 2 \mathrm{DMF} \cdot 2 \mathrm{H}_{2} \mathrm{O} .^{16}$

The effect of the counter ion on the nonlinear optical response has been briefly investigated in the literature. In the case of second order nonlinearities, in ferrocenyl complexes, the differences in the response have been attributed to the noncentrosymmetrical nature of the counter ion ${ }^{19}$ which cannot be the case in the present study. Moreover, as it has been stated in Ref. 19, the ion pairing is likely to contribute to the NLO response of the complexes. We, therefore, believe that in the case of Au-Mel in the current work, the charge assisted hydrogen bonding is playing an important role in the NLO response. Moreover, in another work by Cifuentes et al., ${ }^{20}$ which was carried out by means of the Z-scan technique using fs laser pulses, several molecular structures containing different counter ions have been investigated. The authors concluded that the relation between the third order nonlinear susceptibility and the nature of the counter ion has not been clear cut, probably because of the lack of any crystal structure characterization.

The magnitude of the third order nonlinear optical response of the dithiolenes can be highly dependent upon the structure of the molecules, the ligands employed to engineer them, as well as their absorption spectrum features. ${ }^{12,14}$ The order of magnitude of the $\gamma$ values $\left(10^{-32} \mathrm{esu}\right)$ found here for the two dithiolene complexes is correlated with the fact that 
there is no resonance enhancement of the nonlinear optical response, however, higher values can be achieved when the laser excitation wavelength is in resonance with an absorption band of the system. In the literature, few reported works exist concerning the nonlinearity of gold dithiolene complexes (see, for example, Refs. 13 and 14). Chatzikyriakos et al. ${ }^{13}$ have investigated the nonlinearity of an $\mathrm{Au}(\mathrm{dpedt})_{2}$ complex and they reported a $1.53 \times 10^{-32}$ esu value for the second hyperpolarizability at $532 \mathrm{~nm}, 35$ ps laser excitation, which is in very good agreement with our results obtained in this work. Moreover, the nonlinear absorption is negligible compared with the nonlinear refraction up to the maximum concentration investigated $(1.64 \mathrm{mM})$, which is also in agreement with our finding that no nonlinear absorption has been found, up to $1.5 \mathrm{mM}$ concentration.

In conclusion, we have investigated the nonlinear optical response of two gold dithiolene complexes, which differ by the nature of the counter cations that introduce different type of hydrogen bonding interactions with the anionic complex. This has been found to result in significant modification of the nonlinear optical response. The possibility to modify the nonlinear optical response of these systems by changing their structural arrangement opens wide prospects for utilizing such molecules for photonic applications.

K.I. acknowledges support from the European Commission and General Secretariat for Research and Technology (Greece) for a National Strategic Reference Framework (NSRF) project (PE3-(1612)).

${ }^{1}$ Organic Thin Films for Waveguiding Nonlinear Optics, edited by F. Kajzar and J. D. Swalan (Gordon and Breach, New York, 1996).
${ }^{2}$ Characterization Techniques and Tabulations for Organic Nonlinear Optical Materials, edited by M. G. Kuzyk and C. W. Dirk (Marcel Dekker, Inc., 1998).

${ }^{3}$ J. V. Moloney, Nonlinear Optical Materials (Springer, New York, 1998).

${ }^{4}$ I. Fuks-Janczarek, J. Luc, B. Sahraoui, F. Dumur, P. Hudhomme, J. Berdowski, and I. V. Kityk, J. Phys. Chem. B 109, 10179 (2005).

${ }^{5}$ B. Sahraoui, I. Fuks-Janczarek, S. Bartkiewicz, K. Matczyszyn, J. Mysliwiec, I. V. Kityk, J. Berdowski, E. Allard, and J. Cousseau, Chem. Phys. Lett. 365, 327 (2002).

${ }^{6}$ K. Iliopoulos, R. Czaplicki, H. El Ouazzani, J. Y. Balandier, M. Chas, S. Goeb, M. Salle, D. Gindre, and B. Sahraoui, Appl. Phys. Lett. 97, 101104 (2010).

${ }^{7}$ C. S. Winter, C. A. S. Hill, and A. E. Underhill, Appl. Phys. Lett. 58, 107 (1991).

${ }^{8}$ H. Tanaka, Y. Okano, H. Kobayashi, W. Suzuki, and A. Kobayashi, Science 291, 285 (2001).

${ }^{9}$ A. Kobayashi, E. Fujiwara, and H. Kobayashi, Chem. Rev. 104, 5243 (2004).

${ }^{10}$ A. E. Underhill, J. Mater. Chem. 2 , 1 (1992).

${ }^{11}$ R. P. Shibaeva and E. B. Yagubskii, Chem. Rev. 104, 5347 (2004).

${ }^{12}$ Z. Dai, X. Yue, B. Peng, Q. Yang, X. Liu, and P. Ye, Chem. Phys. Lett. 317, 9 (2000).

${ }^{13}$ G. Chatzikyriakos, I. Papagiannouli, S. Couris, G. C. Anyfantis, and G. C. Papavassililiou, Chem. Phys. Lett. 513, 229 (2011).

${ }^{14}$ L. Hu, J. Qin, N. Zhou, Y.-F. Meng, Y. Xu, J.-L. Zuo, and X.-Z. You, Dyes Pigm. 92, 1223 (2012).

${ }^{15}$ G. Soras, N. Psaroudakis, G. A. Mousdis, M. J. Manos, A. J. Tasiopoulos, P. Aloukos, S. Couris, P. Labéguerie, J. Lipinski, A. Avramopoulos, and M. G. Papadopoulos, Chem. Phys. 372, 33 (2010).

${ }^{16}$ A. Rangananthan, A. El-Ghayoury, L. Zorina, and P. Batail, Cryst. Eng. Comm. 12, 4268 (2010).

${ }^{17}$ M. Sheik-Bahae, A. A. Said, T. H. Wei, D. J. Hagan, and E. W. Van Stryland, IEEE J. Quantum Electron. 26, 760 (1990).

${ }^{18}$ G. Bruno, M. Almeida, D. Simao, M. L. Mercuri, L. Pilia, A. Serpe, and P. Deplano, Dalton Trans. 2009, 495.

${ }^{19}$ J. A. Mata, E. Peris, S. Uriel, R. Llusar, I. Asselberghs, and A. Persoons, Polyhedron 20, 2083 (2001).

${ }^{20}$ M. P. Cifuentes, J. Driver, M. G. Humphrey, I. Asselberghs, A. Persoons, M. Samoc, and B. Luther-Davies, J. Organomet. Chem. 607, 72 (2000). 